\title{
Helminth infections and type 2 diabetes: a cluster-randomized placebo controlled SUGARSPIN trial in Nangapanda, Flores, Indonesia
}

Dicky L Tahapary ${ }^{1,2+}$, Karin de Ruiter ${ }^{2+}$, Ivonne Martin ${ }^{3,4}$, Lisette van Lieshout ${ }^{2}$, Bruno Guigas ${ }^{2,5}$,

Pradana Soewondo ${ }^{1}$, Yenny Djuardi ${ }^{6}$, Aprilianto E Wiria ${ }^{6}$, Oleg A Mayboroda ${ }^{7}$, Jeanine J Houwing-Duistermaat ${ }^{3}$, Hengki Tasman ${ }^{8}$, Erliyani Sartono ${ }^{2}$, Maria Yazdanbakhsh², Johannes W A Smit ${ }^{9,10^{*}+}$ and Taniawati Supali $i^{*^{*}}$

\begin{abstract}
Background: Insulin resistance is a strong predictor of the development of type 2 diabetes mellitus. Chronic helminth infections might protect against insulin resistance via a caloric restriction state and indirectly via T-helper-2 polarization of the immune system. Therefore the elimination of helminths might remove this beneficial effect on insulin resistance.

Methods/Design: To determine whether soil-transmitted helminth infections are associated with a better whole-body insulin sensitivity and whether this protection is reversible by anthelmintic treatment, a household-based cluster-randomized, double blind, placebo-controlled trial was conducted in the area of Nangapanda on Flores Island, Indonesia, an area endemic for soil-transmitted helminth infections. The trial incorporates three monthly treatment with albendazole or matching placebo for one year, whereby each treatment round consists of three consecutive days of supervised drug intake. The presence of soil-transmitted helminths will be evaluated in faeces using microscopy and/or PCR. The primary outcome of the study will be changes in insulin resistance as assessed by HOMA-IR, while the secondary outcomes will be changes in body mass index, waist circumference, fasting blood glucose, 2 h-glucose levels after oral glucose tolerance test, HbA1c, serum lipid levels, immunological parameters, and efficacy of anthelmintic treatment.

Discussion: The study will provide data on the effect of helminth infections on insulin resistance. It will assess the relationship between helminth infection status and immune responses as well as metabolic parameters, allowing the establishment of a link between inflammation and whole-body metabolic homeostasis. In addition, it will give information on anthelmintic treatment efficacy and effectiveness.

Trial registration: This study has been approved by the ethical committee of Faculty of Medicine Universitas Indonesia (ref: 549/H2.F1/ETIK/2013), and has been filed by the ethics committee of Leiden University Medical Center, clinical trial number: ISRCTN75636394. The study is reported in accordance with the CONSORT guidelines for cluster-randomised trials.
\end{abstract}

Keywords: Insulin resistance, Helminth, Type 2 diabetes, Parasite, Metabolism, Albendazole, Immunology

\footnotetext{
* Correspondence: jan.smit@radboudumc.nl; taniawati@yahoo.com

${ }^{\dagger}$ Equal contributors

${ }^{9}$ Department of Internal Medicine, Radboud University Medical Centre,

Nijmegen, The Netherlands

${ }^{6}$ Department of Parasitology, Faculty of Medicine, Universitas Indonesia,

Jakarta, Indonesia

Full list of author information is available at the end of the article
} 


\section{Background}

The number of people with diabetes mellitus is increasing worldwide [1-3]. At present, $8.3 \%$ of adults (382 million people) have diabetes mellitus [4] and Asia is a major site of this rapidly emerging epidemic [5]. In many Asian countries, including Indonesia, rapid socio-economic development has led to a shift in infrastructure, technology and introduction of Western style diets, which promotes overnutrition and sedentary lifestyles [5-8]. These changes have already led to an increasing prevalence of diabetes mellitus in Indonesia [9-12].

A strong predictor for the development of type 2 diabetes mellitus (DM2) is insulin resistance [13,14], which is caused by complex disturbances in multiple biological systems. There is now abundant evidence that inflammation [15] plays a role in the development of DM2, in addition to the more established relationship between an altered energy balance resulting from excess consumption of high-energy foods and/or decreased physical activity. In DM2 subjects, chronic low-grade inflammation is a common feature [15] which results, at least in part, from the activation of inflammatory pathways by fatty acids in multiple organs [16-18]. However, the fundamental molecular mechanisms are still incompletely understood [19].

In developing countries, infectious pressure might be one particular modifier of insulin resistance. Helminth infections, which are still endemic in many low to middle income countries, may therefore affect whole-body and tissue-specific insulin sensitivity owing to their immunomodulatory properties [20]. Previous studies have shown that helminth infections can adopt an immune evasion strategy by inducing regulatory $\mathrm{T}$ cells [21-26]. Hereby helminth infections may decrease systemic inflammation and subsequently the development of inflammatory diseases, including DM2 [27-30]. Studies examining the relationship between helminth infections and DM2 in both humans [31,32] and murine models [33,34] support this hypothesis. At a molecular level, mTOR, a serine/ threonine protein kinase located downstream of insulin signalling, plays an essential role in immune cell energy metabolism and function [35,36]. Furthermore, it has been shown that STAT6 signalling downstream of IL-4, as well as Th2 responses induced by helminths, improve glucose metabolism and insulin signalling [33,37]. Intriguingly, in humans, immune intervention with IL-1 receptor antagonist (Anakinra) has also been shown to influence glucose metabolism [38].

Helminths are also known to reduce energy intake and thereby change the energy balance [39], which may be beneficial in terms of insulin resistance $[39,40]$. Helminths may therefore both directly improve insulin sensitivity via a caloric restriction state and indirectly via Th2 activation. It appears, the immune system which has evolved with helminths [41] and under conditions of low energy intake, seems to be out of balance in situations of nutritional overload and decreasing exposure to parasites [23,42]. In line with the proposed beneficial effects of helminth infections on glucose metabolism, our previous unpublished cross sectional study in Flores Island, Indonesia, has shown that subjects infected with intestinal helminths have a significantly lower insulin resistance as expressed by HOMA-IR.

Although aforementioned studies strongly suggest that there is an association between helminth infections, systemic inflammation and glucose metabolism, the causality in these relationships has not been demonstrated as yet. Therefore we have initiated a large scale cluster randomized controlled trial (RCT) with the aim to assess the effect of anthelmintic treatment on insulin resistance, the hypothesis being that reduction of worm load to undetectable levels will lead to a higher degree of insulin resistance. While study outcomes will be analysed at the individual participant level, a household cluster randomization was chosen to minimise contamination between treatment groups and therefore reinfection of treated individuals.

\section{Study design \\ Study area}

The study area is located in Nangapanda, a sub-district of the Ende District of Flores Island, Indonesia [43,44]. Nangapanda is a semi-urban coastal area with a population of approximately 22.000 people being divided over 29 villages. Our study area includes three of these villages (Ndeturea, Ndorurea 1, Ndorurea), with a total population of 3698 people, from which most of the adult population are farmers. Previous studies have shown that this area is endemic for soil-transmitted helminth (STH) infections [45]. A detailed map of the study area has been published [43].

\section{Trial design}

The study is designed as a household-based clusterrandomized, double-blind trial with two arms. In one arm treatment is given with albendazole (single dose of $400 \mathrm{mg}$ ) on 3 consecutive days, while the other arm consists of matching placebo treatment (both albendazole and placebo are manufactured by PT Indofarma Pharmaceutical, Bandung, Indonesia). The treatment is provided every three months for a period of 1 year (total 4 rounds) to all household members except children below 2 years of age, while subjects aged 16 and above will undergo clinical and laboratory examination. Subjects with active treatment for diabetes mellitus, serious concomitant disease and pregnancy will be excluded.

The population was randomised by JWAS and JJH using computer aided block randomization at household level, utilizing Random Allocation Software to assign treatment groups. Both study investigators and patients are blinded 
for treatment codes. The treatment code will be unblinded when all data needed for analysis are cleaned and entered into the database. An additional randomization was performed in a subgroup of individuals, who will undergo an oral glucose tolerance test and immunological studies in order to study glucose metabolism and immune mechanisms in more detail. For this subgroup, we aimed to select one subject per household and stratified by age group (1636 years of age, $36-56$ years of age, and $>56$ years of age) to ensure that sufficient numbers of all age groups are participating. Randomization was based on households.

Well trained community workers were recruited and trained to distribute the drugs. These workers were also trained to assist during clinical examination and sample collection and were involved in health promotion within the population. Community workers and research team members will directly supervise the study participants while taking the study medication, and will collect empty drug canisters at each visit to confirm compliance. Furthermore, assessment of side effects will take place during these visits and migration and death will be noted. Adverse events spontaneously reported by the patient or observed by the investigators, will be monitored throughout the study. After completion of the study, the whole study population will be treated with a single dose of albendazole $(400 \mathrm{mg})$ for 3 consecutive days.

\section{Outcomes}

As this study aims to assess the effect of anthelmintic treatment on whole-body insulin sensitivity, our primary outcome is a change in insulin resistance as assessed by HOMA-IR between both treatment arms after one year of treatment. Secondary outcomes are changes in body mass index and waist circumference, fasting blood glucose, 2 h-glucose levels after oral glucose tolerance test, HbA1c, serum lipid levels, immunological parameters, and efficacy of anthelmintic treatment.

\section{Sample size}

Sample size is calculated according to intention to treat analysis in which we will need 1580 subjects in total. Based on our previous study [45] we assume that the average household size is 4 and that around $20 \%$ will be lost to follow up after one year. We use a significance level of $5 \%$ and a power of $80 \%$. Correlations within households are taken into account by using the correction factor $1+(m-1)$ ICC, with $m$ being the household size and ICC the intra-class correlation. The sample size is computed for a difference in mean between the two treatment groups of 0.18 and an ICC of 0.1 .

For the subgroup of individuals undergoing an oral glucose tolerance test, a sample size of 335 subjects in total is calculated assuming that around $20 \%$ will be lost to follow up after one year and using a significance level of $5 \%$ and a power of $80 \%$. The sample size is computed for a difference in mean of $10.3 \mathrm{mg} / \mathrm{dL}$ and a standard deviation of glucose level of $30 \mathrm{mg} / \mathrm{dL}$.

\section{Methods}

\section{Sample collection}

At baseline all eligible subjects, aged 16 and above will be invited to visit the examination centre after an overnight fasting and to provide stool, blood and first morning urine samples. During this visit, participant's education level and profession will be registered. After 1 year of treatment follow-up sample collection will take place as shown in Table 1.

\section{Clinical anthropometry assessment}

Anthropometric measurements of body weight, height, waist and hip circumference are obtained using the National Heart, Lung, and Blood Institute (NHLBI) practical guidelines. To measure body weight a flat scale for mobile use (SECA Model 876, Seca Gmbh Co, Hamburg, Germany) is used, while a portable stadiometer (SECA Model 213, Seca Gmbh Co, Hamburg, Germany) is used to measure height. Waist and hip circumference are measured using ergonomic circumference measuring tape (SECA Model 201, Seca Gmbh Co, Hamburg, Germany). In addition, body fat composition is measured using a Tanita body composition analyser (TBF-300A, Tanita Corp, Tokyo, Japan). Three blood pressure measurements (left arm, sitting upright position, after resting 5 minutes) are taken from each subject, using a digital sphygmomanometer (HEM-7200, Omron Healthcare Co, Ltd, Kyoto, Japan), and calibrated using a Riester nova-presameterHDesk model mercury sphygmomanometer (Gerhard Glufke Rudolf Riester $\mathrm{GmbH} \& \mathrm{Co}$, Jungingen, Germany) and a 3MTM LittmannH Classic II S.E. Stethoscope (3 M, St. Paul, Minnesota, USA). The average of three systolic/ diastolic blood pressure measurements will be used for analysis.

\section{Parasitological examination}

To assess intestinal helminth infection, stool containers are distributed and collected by health workers. Stool samples are examined by the Kato Katz method [46] for

Table 1 Study schedule of the Sugarspin project

\begin{tabular}{|c|c|c|c|c|c|c|}
\hline \multirow[t]{2}{*}{ Outcome } & \multirow[t]{2}{*}{ Baseline } & \multicolumn{4}{|c|}{3 monthly treatment } & \multirow{2}{*}{$\begin{array}{l}1 \text { year } \\
\text { follow up }\end{array}$} \\
\hline & & $\overline{1 s t}$ & 2nd & $3 r d$ & 4th & \\
\hline Clinical Anthropometry & $x$ & & & & & $\mathrm{X}$ \\
\hline Parasitological examination & $x$ & & & & & $x$ \\
\hline Metabolic parameters & $x$ & & & & & $x$ \\
\hline Immunological parameters & $\mathbf{X}$ & & & & & $x$ \\
\hline Assessment of side effects & & $\mathrm{X}$ & $\mathbf{X}$ & $\mathbf{x}$ & $\mathrm{X}$ & $\mathrm{X}$ \\
\hline
\end{tabular}


identification and quantification of STH eggs using 2 slides for each sample. An aliquot of the fresh stool samples is frozen at $-20^{\circ} \mathrm{C}$ in the field and subsequently at $-80^{\circ} \mathrm{C}$ in laboratories of the Departments of Parasitology at Leiden University Medical Center, Leiden, The Netherlands and Faculty of Medicine Universitas Indonesia, Jakarta, Indonesia for DNA extraction [43]. Part of the stool sample will be saved for potential future analysis of the microbiome.

\section{DNA isolation and helminth real-time $P C R$}

DNA isolation from stool will be performed as described elsewhere [43], with some minor modifications. Realtime PCR will be performed to detect the presence of $A$. duodenale, N. americanus (hookworm), A. lumbricoides and T. trichiura using a method described previously [43] with some modifications.

\section{Blood collection}

Peripheral blood is collected into EDTA and SST Vacutainers (BD, Franklin Lakes, NJ, USA). Giemsa-stained peripheral blood smear is prepared to evaluate neutrophil and eosinophil counts. In a subset of the study population, additional blood is collected in PAXgene Blood RNA Tubes (PreAnalytiX GmbH, Hombrechtikon, Switzerland) and Sodium Heparin Vacutainers (BD). Blood collected in PAXgene Blood RNA Tubes will be used to study RNA expression profiles, while blood collected in Sodium Heparin Vacutainers will be used for detailed immunological measurements as described below (section Immunological methods). All samples deriving from EDTA and SST Vacutainers (serum, plasma, cell pellet and whole blood) and all PAXgene Blood RNA Tubes are kept at $-20^{\circ} \mathrm{C}$ at the Field Clinical Research Centre (FCRC) and will be sent on dry ice to the University's laboratory for storage at $-80^{\circ} \mathrm{C}$.

\section{Metabolic parameters}

Fasting blood glucose is measured in capillary blood using Breeze 2 glucose meters (Bayer Health Care LLC, Basel, Switzerland). An oral glucose tolerance test is performed in a subset of the study population according to the WHO protocol $[47,48]$. Glucose levels are measured in capillary blood using Breeze 2 glucose meters after overnight fasting and 2 hours after ingesting $75 \mathrm{~g}$ of anhydrous glucose dissolved in $200 \mathrm{cc}$ of water. Insulin, HbA1c and lipid profiles will be measured in an internationally accredited laboratory. HOMA-IR, a well-validated measure of insulin resistance will be calculated to estimate insulin resistance [49].

\section{Immunological methods}

The immunological parameters that will be studied are 1) Total IgE levels as one of the markers of a Th2 response and its relation to metabolic parameters, 2)
Circulating pro- and anti-inflammatory cytokines in order to study their relationship to metabolic parameters, 3) Antigen specific IgE and IgG to Ascaris lumbricoides to monitor antibody responses to one of the helminths studied as a marker of changing immune responses as a result of anthelmintic treatment, 4) Granulocyte (neutrophil and eosinophil) frequencies and their activation to assess whether granulocytes, in particular eosinophils which are associated with Th2 response, are linked to helminth infections and metabolic parameters, 5) Peripheral blood mononuclear cells (PBMC) subset analysis and polarisation by flow cytometry in order to assess the relationship between immune cell frequencies ( $\mathrm{T}$ cell subsets, B cell subsets, monocyte subsets, NK cells and myeloid suppressor cells) in situ as well as after activation and metabolic parameters.

\section{Total IgE}

Total IgE will be measured using ELISA with rabbit anti-human IgE antibodies (Dako, Glostrup, Denmark) and goat anti-human IgE biotinylated antibodies (Vector Laboratories, Burlingame, CA, USA) as capture and detection antibodies, as described previously [43]. The World Health Organization standard of human serum IgE was used as a reference (National Institute for Biological Standards and Control). The results will be expressed in International Units (IU).

\section{Circulating cytokines}

Pro and anti-inflammatory cytokines (TNF $\alpha$, IFN $\gamma$, IL-1, IL-6, IL-10, TGF $\beta$ ) will be measured in serum samples using cytokine kits with high sensitivity.

\section{Ascaris-specific lgE}

Ascaris antigen will be prepared from Ascaris lumbricoides worms as described previously [50]. Maxisorp plates (Thermo Fisher Scientific, Roskilde, Denmark) will be coated overnight with $5 \mu \mathrm{g} / \mathrm{ml}$ Ascaris antigen in $0.1 \mathrm{M}$ carbonate buffer ( $\mathrm{pH}$ 9.6). Plates will be blocked for 1 hour with PBS containing 2\% bovine serum albumin. Samples will be diluted $1 / 60$ in $0.1 \mathrm{M}$ Tris- $\mathrm{HCl}$ containing $0.05 \%$ Tween-20 and incubated overnight together with a pool of positive standard plasma containing $1 \times 10^{6}$ arbitrary units (AU) parasite specific IgE. After a washing step, goat anti-human IgE biotinylated antibodies (Vector) will be incubated followed by streptavidin-HRP (Sanquin, Amsterdam, the Netherlands). The color is developed by adding 3,3',5,5' tetramethylbenzidine (TMB) (KPL, Gaithersburg, MD, USA). The reaction will be stopped by adding $1.8 \mathrm{M} \mathrm{H}_{2} \mathrm{SO}_{4}$ and absorbance will be read at $450 \mathrm{~nm}$ in an automated plate reader. 


\section{Ascaris-specific lgG isotypes}

Maxisorp plates will be coated with Ascaris antigen as described for Ascaris specific IgE above. Blocking will be done using PBS containing $5 \%$ bovine serum albumin. Samples will be diluted $1 / 1000,1 / 10,1 / 5$ or $1 / 25$ for IgG1, IgG2, IgG3 and IgG4 respectively, and a pool of positive standard plasma containing $1 \times 10^{6}$ arbitrary units (AU) parasite specific IgG isotypes will be included in each plate. After overnight incubation, HRP-labelled anti human IgG isotypes (Sanquin) in PBS $0.05 \%$ Tween20 will be added for 4 hours incubation at $37^{\circ} \mathrm{C}$ using the following dilutions: 1/3000 for anti IgG1 (HP6188) and anti IgG4 (HP6196); 1/1000 for anti IgG2 (HP6014) and anti IgG3 (HP6095). TMB substrate will be used to develop the color and the reaction will be stopped as described above.

\section{Whole blood stimulation and fixed granulocyte cryopreservation}

To study the expression of activation markers on granulocytes, $600 \mu \mathrm{l}$ of heparinised venous blood is divided over 3 polystyrene tubes $(200 \mu \mathrm{l} /$ tube). After a preincubation of 5 minutes in a $37^{\circ} \mathrm{C}$ waterbath, a 5 minutes stimulation at $37^{\circ} \mathrm{C}$ is performed with N-Formyl-MetLeu-Phe (FMLP, $10^{-5} \mathrm{M}$; Sigma, Saint Louis, MO, USA) or eotaxin $\left(10^{-7} \mathrm{M}\right.$; R\&D systems, Abingdon, UK). Subsequently, $4 \mathrm{ml}$ of FACS lysing solution (BD) is added and after an incubation period of 15 minutes at room temperature the red blood cells is lysed while white blood cells, including granulocytes, become fixed. Cells are washed with RPMI 1640 containing 10\% heatinactivated FCS and then resuspended in RPMI 1640 containing $10 \%$ of heat-inactivated foetal calf serum (FCS) and 10\% dimethyl sulfoxyde (DMSO). Cryovials containing the cell suspension are placed at $-80^{\circ} \mathrm{C}$ for minimum of 4 hours, followed by storage in liquid nitrogen until analysis.

\section{PBMC cryopreservation}

Peripheral blood mononuclear cells (PBMCs) are isolated from heparinised venous blood using Ficoll density gradient centrifugation within 12 hours after blood collection. After isolation, cells are cryopreserved in RPMI 1640 containing $20 \%$ of heat-inactivated foetal calf serum (FCS) and 10\% dimethyl sulfoxyde (DMSO). Cryovials containing the cell suspension are transferred to a freezing unit which is placed in a $-80^{\circ} \mathrm{C}$ freezer for minimum of 4 hours. Subsequently, vials are stored in liquid nitrogen until analysis.

\section{Metabolomics for metabolic profiling}

Urine samples and blood samples from heparinized blood are kept at $-20^{\circ} \mathrm{C}$ at the FCRC and subsequently stored at $-80^{\circ} \mathrm{C}$ at the University's laboratory for future metabolomics measurements. The exploratory metabolomics analysis will be performed by $1 \mathrm{H}-\mathrm{NMR}$ and LCMS metabolomics, a combination of NMR and LC-MS proposed for this study provides a comprehensive coverage of metabolome and as such increase the probability

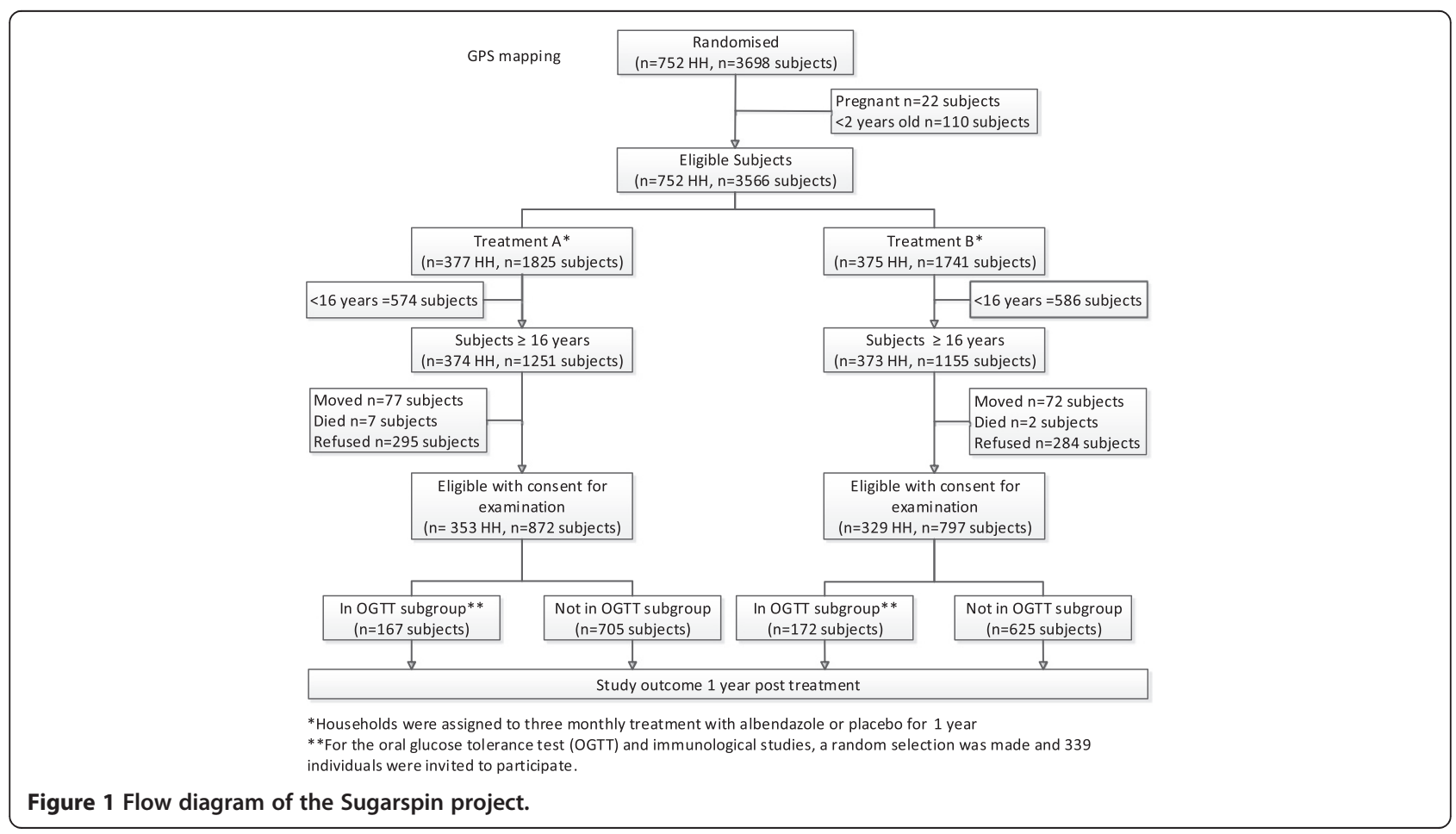



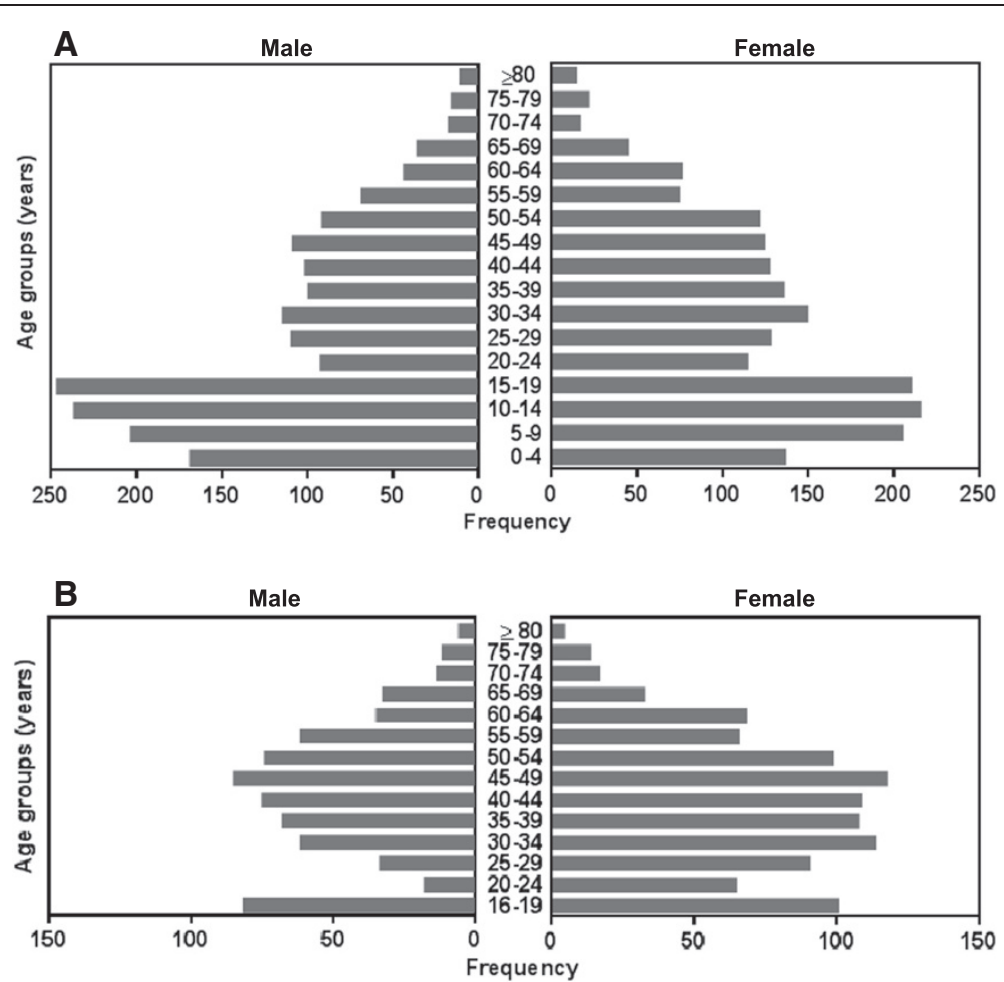

Figure 2 Age pyramid. Age pyramid of all individuals living in the study area in Nangapanda, Flores Island, Indonesia ( $\mathrm{n}=3698$ subjects, 52\% female) (A), and of study participants ( $n=1669$ subjects, 60\% female) (B).

of finding physiologically meaningful associations within the data.

\section{Data management and statistical analyses}

A centrally accessible database designed in Microsoft Access is established and the data is entered by well-trained data entry personnel. Descriptive data will be summarized for continuous variables as mean +/- SD for normally distributed data and median (range) for non-normally distributed data. Categorical data will be expressed as proportions.

The effect of anthelmintic treatment on insulin resistance (HOMA-IR) as our primary outcome will be assessed using an intention to treat approach after 1 year of treatment using mixed models to account for the correlation within households, in which relevant confounders



Profession
$\square$ Farmer
$\square$ Fisherman
$\square$ Government employee
$\square$ Private employee
$\square$ Merchant
$\square$ House wife
$\boxminus$ Student
$\square$ No job
$\square$ Other
$\square$ Unknown

Figure 3 Job distribution. At baseline, profession was assessed for study participants ( $n=1669$ subjects). 


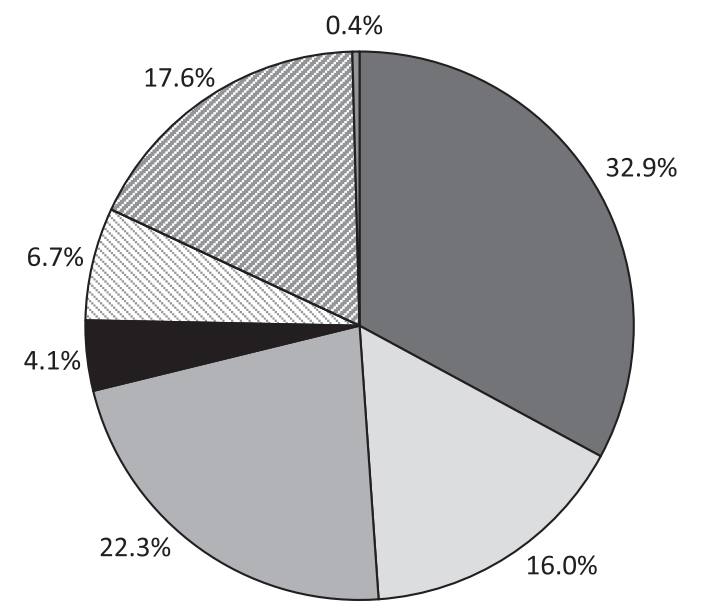

\author{
Education level \\ 口Elementary school \\ $\square$ Junior high school \\ $\square$ Senior high school \\ - Academy \\ QUniversity \\ 口 Illiterate or drop out \\ 口Unknown
}

Figure 4 Education level. At baseline, education level was assessed for study participants ( $n=1669$ subjects).

(including age, gender, BMI, village) are entered. The characterization of immune responses to helminth infections and systemic inflammation will be assessed by measuring cytokine profiles. Moreover, for these analyses multilevel modelling will be used and the use of longitudinal data will take repeated measurement into account [51]. The mediation of helminth's effects on insulin resistance via immune responses will also be assessed.

\section{Ethical approval, trial registration and consent}

This study has been approved by The Health Research Ethical Committee, Faculty of Medicine, Universitas Indonesia Cipto Mangunkusumo Hospital, Jakarta, Indonesia (reference number:549/H2.F1/ETIK/2013). It has also been filed by the ethics committee of Leiden University Medical Center and is registered as a clinical trial ref: ISRCTN75636394 (http://www.isrctn.com/ ISRCTN75636394). The local health authorities have been informed about this study and have given their approval and support. The study, its benefits and risks are explained to the population and consent forms are distributed to be signed by the subjects who are willing to participate in this study. They are informed that they can withdraw from the study at any time, for any reasons and without any consequences.

\section{Description of the population recruited}

So far, the study has provided the following data (Figure 1). At baseline, a total of 3698 individuals were registered in 752 households. Of the 2428 subjects aged 16 years or older, 1669 subjects were eligible with consent for examination. For the oral glucose tolerance test and immunological studies 339 subjects were randomly selected and gave approval.

Figure 2 shows the age pyramid of both the total population in the study area and the study population.
In the study population farming and fishing are the traditional source of income while some individuals engage in jobs at government offices or in the private sector (Figure 3), a similar distribution is seen in the total population. The education level of the majority of subjects in the study population is elementary school (33\%), followed by senior high school (22\%), and junior high school $(16 \%)$, while $11 \%$ has college or university degrees. Moreover, $18 \%$ of the subjects is illiterate, either not educated at all or dropped out from elementary school (Figure 4). A similar distribution of the education level is seen in the total population.

\section{Discussion}

The SUGARSPIN trial is the first and currently the only longitudinal study investigating the effects of anthelmintic treatment on whole-body insulin sensitivity. This placebocontrolled trial enables us for the first time to investigate the causal relationship between helminth infections, systemic inflammation and glucose metabolism in humans. In addition, this study will provide data on anthelmintic treatment efficacy and effectiveness in a large population in a developing country like Indonesia.

\section{Abbreviations}

DM2: Type 2 diabetes mellitus; FCRC: Field clinical research center; OGTT: Oral glucose tolerance test; STH: Soil-transmitted helminth; Th2: T-helper-2.

\section{Competing interests}

The authors declare that they have no competing interests.

\section{Authors' contributions}

DLT is a medical doctor in charge of the field study, involved in setting up the study, supervising gathering of data, treatment, clinical care, follow up of the study population and wrote the paper. KR is a medical biologist in charge of the field study, involved in setting up the laboratory in the study area, performing the immunological analysis, supervising the data cleaning, follow up of the study population and wrote the paper. IM is a mathematician who is developing methods to analyse the complex data generated during the lifetime of the project and involved in the randomization. $L V L$ is a parasitologist 
who is involved in the performance and analysis of diagnostic assays for the detection of helminths in stool samples. BG is a biologist who advises on the metabolic aspects of the study. PS is an endocrinologist who advises on the metabolic aspects of the study. YD is a medical doctor who is involved in coordinating the study and advises on the immunological and parasitological aspects of the study. AEW is a medical doctor who is involved in clinical care and setting up the database. OM is a biochemist who advises on the metabolomics studies in urine and serum. JJH is a biostatistician who developed the study, and is involved in supervising sample size calculation, randomization and statistical analysis. HT is a mathematician who is in charge of census and GPS-mapping. ES is an immunoparasitologist who is involved in coordinating the study and advising on parasitological and immunological aspects of the study and supervised the writing of the manuscript. MY is an immunologist who developed the study, supervised the writing of the manuscript and and is the scientific coordinator of the SUGARSPIN program. JWAS is an endocrinologist who developed the study, supervised the writing of the manuscript, and is the Dutch coordinator of the SUGARSPIN program. TS is a parasitologist who developed the study and is the Indonesian coordinator of the SUGARSPIN program. All authors read and approved the final manuscript.

\section{Authors' information}

Dicky and Karin are equal contributors in writing the manuscript, while Johanes WA Smit and Taniawati Supali are equal contributors in the term of coordinators of the project from The Netherlands and Indonesian side.

\section{Acknowledgements}

This study is funded by The Royal Netherlands Academy of Arts and Science (KNAW), Ref 57-SPIN3-JRP and Universitas Indonesia (Research Grant BOPTN 2742/ H2.R12/HKP.05.00/2013.). The authors thank The Indonesian Directorate General of Higher Education (DIKTI) for providing scholarship to two PhD candidates involved in this project. The authors thank Bernadus Idu as the head of sub district Nangapanda for his support, as well as to Yusuf Gedu, Husni Abdullah, Suparti as the head of village Ndeturea, Ndorurea 1 and Ndorurea respectively. Dr. Helda Sihotang and Dr Agus Tobing, as well as all health workers in Nangapanda's Community Health Centre and Octavia as the responsible person for data entry. All local field workers, the UI team (Sudirman, Suwarto, Yosi Destani, Eka S Mulyawan, Clara C. Djimandjaja, Femmy Pical, Rospita Maylasari, Difa Stefanie, Sovia N. Linda, Budi Prasetyo) and Yvonne Kruize. Most of all, thanks to all inhabitants of Nangapanda.

\section{Author details}

${ }^{1}$ Department of Internal Medicine, Faculty of Medicine, Universitas Indonesia, Jakarta, Indonesia. ${ }^{2}$ Department of Parasitology, Leiden University Medical Center, Leiden, The Netherlands. ${ }^{3}$ Department of Medical Statistics and Bioinformatics, Leiden University Medical Center, Leiden, The Netherlands. ${ }^{4}$ Department of Mathematics, Parahyangan Catholic University, Bandung, Indonesia. ${ }^{5}$ Department of Molecular Cell Biology, Leiden University Medical Center, Leiden, The Netherlands. ${ }^{6}$ Department of Parasitology, Faculty of Medicine, Universitas Indonesia, Jakarta, Indonesia. ${ }^{7}$ Center for Proteomics and Metabolomics, Leiden University Medical Center, Leiden, The Netherlands. ${ }^{8}$ Department of Mathematics, Faculty of Mathematics and Natural Science, Universitas Indonesia, Jakarta, Indonesia. ${ }^{9}$ Department of Internal Medicine, Radboud University Medical Centre, Nijmegen, The Netherlands. ${ }^{10}$ Department of Internal Medicine, Leiden University Medical Center, Leiden, The Netherlands.

\section{Received: 24 February 2015 Accepted: 9 March 2015} Published online: 18 March 2015

\section{References}

1. Guariguata L, Whiting DR, Hambleton I, Beagley J, Linnenkamp U, Shaw JE. Global estimates of diabetes prevalence for 2013 and projections for 2035. Diabetes Res Clin Pract. 2014;103:137-49.

2. Guariguata L. By the numbers: new estimates from the IDF Diabetes Atlas Update for 2012. Diabetes Res Clin Pract. 2012;98:524-5.

3. Shaw JE, Sicree RA, Zimmet PZ. Global estimates of the prevalence of diabetes for 2010 and 2030. Diabetes Res Clin Pract. 2010;87:4-14.

4. International Diabetes Federation. IDF diabetes atlas. 6th ed. Brussels, Belgium: International Diabetes Federation; 2013.
5. Chan JC, Malik V, Jia W, Kadowaki T, Yajnik CS, Yoon KH, et al. Diabetes in Asia: epidemiology, risk factors, and pathophysiology. JAMA. 2009;301:2129-40.

6. Chan JC. Diabetes in Asia: from understanding to action. Ann Acad Med Singapore. 2008;37:903-5.

7. Ramachandran A, Snehalatha C, Shetty AS, Nanditha A. Trends in prevalence of diabetes in Asian countries. World J Diabetes. 2012;3:110-7.

8. Soewondo P, Ferrario A, Tahapary DL. Challenges in diabetes management in Indonesia: a literature review. Global Health. 2013;9:63.

9. Badan Penelitian dan Pengembangan Kesehatan KKRI. Riset Kesehatan Dasar (Riskesdas) 2013. 2013. http://www.litbang.depkes.go.id/sites/ download/rkd2013/Laporan_Riskesdas2013.PDF. Accessed 28 January 2015.

10. Mihardja L, Soetrisno U, Soegondo S. Prevalence and clinical profile of diabetes mellitus in productive aged urban Indonesians. J Diabetes Investig. 2014;5:507-12.

11. Mihardja L, Delima, Manz HS, Ghani L, Soegondo S. Prevalence and determinants of diabetes mellitus and impaired glucose tolerance in Indonesia (a part of basic health research/Riskesdas). Acta Med Indones. 2009;41:169-74.

12. Pramono LA, Setiati S, Soewondo P, Subekti I, Adisasmita A, Kodim N, et al. Prevalence and predictors of undiagnosed diabetes mellitus in Indonesia. Acta Med Indones. 2010;42:216-23.

13. Kim CH, Kim HK, Kim EH, Bae SJ, Park JY. Relative contributions of insulin resistance and beta-cell dysfunction to the development of Type 2 diabetes in Koreans. Diabet Med. 2013;30:1075-9.

14. Reddy KJ, Singh M, Bangit JR, Batsell RR. The role of insulin resistance in the pathogenesis of atherosclerotic cardiovascular disease: an updated review. J Cardiovasc Med (Hagerstown). 2010;11:633-47.

15. Calle MC, Fernandez ML. Inflammation and type 2 diabetes. Diabetes Metab. 2012;38:183-91.

16. Cruz NG, Sousa LP, Sousa MO, Pietrani NT, Fernandes AP, Gomes KB. The linkage between inflammation and Type 2 diabetes mellitus. Diabetes Res Clin Pract. 2013;99:85-92.

17. Donath MY, Shoelson SE. Type 2 diabetes as an inflammatory disease. Nat Rev Immunol. 2011;11:98-107.

18. Garcia C, Feve B, Ferre P, Halimi S, Baizri H, Bordier L, et al. Diabetes and inflammation: fundamental aspects and clinical implications. Diabetes Metab. 2010;36:327-38.

19. Aroor AR, McKarns S, Demarco VG, Jia G, Sowers JR. Maladaptive immune and inflammatory pathways lead to cardiovascular insulin resistance. Metabolism. 2013;62:1543-52.

20. Wiria AE, Djuardi Y, Supali T, Sartono E, Yazdanbakhsh M. Helminth infection in populations undergoing epidemiological transition: a friend or foe? Semin Immunopathol. 2012;34:889-901.

21. MacDonald AS, Maizels RM. Alarming dendritic cells for Th2 induction. J Exp Med. 2008;205:13-7.

22. Harn DA, McDonald J, Atochina O, Da'dara AA. Modulation of host immune responses by helminth glycans. Immunol Rev. 2009;230:247-57.

23. van Riet $\mathrm{E}$, Hartgers FC, Yazdanbakhsh M. Chronic helminth infections induce immunomodulation: consequences and mechanisms. Immunobiology. 2007;212:475-90.

24. Everts B, Smits HH, Hokke CH, Yazdanbakhsh M. Helminths and dendritic cells: sensing and regulating via pattern recognition receptors, Th2 and Treg responses. Eur J Immunol. 2010;40:1525-37.

25. Schramm G, Haas H. Th2 immune response against Schistosoma mansoni infection. Microbes Infect. 2010;12:881-8.

26. Wammes $L$, Hamid F, Wiria AE, de Gier B, Sartono E, Maizels RM, et al. Regulatory $T$ cells in human geohelminth infection suppress immune responses to BCG and Plasmodium falciparum. Eur J Immunol. 2010;40:437-42.

27. Wammes L, Mpairwe H, Elliott AM, Yazdanbakhsh M. Helminth therapy or elimination: epidemiological, immunological, and clinical considerations. Lancet Infect Dis. 2014;14(11):1150-62.

28. Wiria AE, Sartono E, Supali T, Yazdanbakhsh M. Helminth infections, type-2 immune response, and metabolic syndrome. PLoS Pathog. 2014;10:e1004140.

29. van den Biggelaar AH, van Ree R, Rodrigues LC, Lell B, Deelder AM, Kremsner PG, et al. Decreased atopy in children infected with Schistosoma haematobium: a role for parasite-induced interleukin-10. Lancet. 2000;356:1723-7.

30. Smits HH, Hammad $H$, van Nimwegen M, Soullie T, Willart MA, Lievers $E$, et al. Protective effect of Schistosoma mansoni infection on allergic airway inflammation depends on the intensity and chronicity of infection. J Allergy Clin Immunol. 2007;120:932-40. 
31. Aravindhan V, Mohan V, Surendar J, Muralidhara RM, Pavankumar N, Deepa M, et al. Decreased prevalence of lymphatic filariasis among diabetic subjects associated with a diminished pro-inflammatory cytokine response (CURES 83). PLoS Negl Trop Dis. 2010;4:e707.

32. Chen Y, Lu J, Huang Y, Wang T, Xu Y, Xu M, et al. Association of previous schistosome infection with diabetes and metabolic syndrome: a cross-sectional study in rural China. J Clin Endocrinol Metab. 2013;98:E283-7.

33. Wu D, Molofsky AB, Liang HE, Ricardo-Gonzalez RR, Jouihan HA, Bando JK, et al. Eosinophils sustain adipose alternatively activated macrophages associated with glucose homeostasis. Science. 2011;332:243-7.

34. Yang Z, Grinchuk V, Smith A, Qin B, Bohl JA, Sun R, et al. Parasitic nematode-induced modulation of body weight and associated metabolic dysfunction in mouse models of obesity. Infect Immun. 2013;81:1905-14.

35. Fox CJ, Hammerman PS, Thompson CB. Fuel feeds function: energy metabolism and the T-cell response. Nat Rev Immunol. 2005;5:844-52.

36. Pearce EL, Walsh MC, Cejas PJ, Harms GM, Shen H, Wang LS, et al. Enhancing CD8 T-cell memory by modulating fatty acid metabolism. Nature 2009;460:103-7.

37. Ricardo-Gonzalez RR, Red EA, Odegaard Jl, Jouihan H, Morel CR, Heredia JE, et al. IL-4/STAT6 immune axis regulates peripheral nutrient metabolism and insulin sensitivity. Proc Natl Acad Sci U S A. 2010;107:22617-22.

38. van Asseldonk EJ, Stienstra R, Koenen TB, Joosten LA, Netea MG, Tack CJ. Treatment with Anakinra improves disposition index but not insulin sensitivity in nondiabetic subjects with the metabolic syndrome: a randomized, double-blind, placebo-controlled study. J Clin Endocrinol Metab. 2011;96:2119-26.

39. Papier K, Williams GM, Luceres-Catubig R, Ahmed F, Olveda RM, McManus DP, et al. Childhood malnutrition and parasitic helminth interactions. Clin Infect Dis. 2014;59:234-43.

40. Alderman $\mathrm{H}$, Konde-Lule J, Sebuliba I, Bundy D, Hall A. Effect on weight gain of routinely giving albendazole to preschool children during child health days in Uganda: cluster randomised controlled trial. BMJ. 2006;333:122.

41. Jackson JA, Friberg IM, Little S, Bradley JE. Review series on helminths, immune modulation and the hygiene hypothesis: immunity against helminths and immunological phenomena in modern human populations: coevolutionary legacies? Immunology. 2009;126:18-27.

42. Maizels RM, Yazdanbakhsh M. Immune regulation by helminth parasites: cellular and molecular mechanisms. Nat Rev Immunol. 2003;3:733-44.

43. Wiria AE, Prasetyani MA, Hamid F, Wammes L, Lell B, Ariawan I, et al. Does treatment of intestinal helminth infections influence malaria? Background and methodology of a longitudinal study of clinical, parasitological and immunological parameters in Nangapanda, Flores, Indonesia (ImmunoSPIN Study). BMC Infect Dis. 2010;10:77.

44. Hamid F, Wiria AE, Wammes L, Kaisar MM, Lell B, Ariawan I, et al. A longitudinal study of allergy and intestinal helminth infections in semi urban and rural areas of Flores, Indonesia (ImmunoSPIN Study). BMC Infect Dis. 2011;11:83.

45. Wiria AE, Hamid F, Wammes LJ, Kaisar MM, May L, Prasetyani MA, et al. The effect of three-monthly albendazole treatment on malarial parasitemia and allergy: a household-based cluster-randomized, double-blind, placebo-controlled trial. PLoS One. 2013;8:e57899.

46. World Health Organization. Bench Aids for the Diagnosis of Intestinal Parasites. Geneva: World Health Organization; 1994.

47. World Health Organization. Definition and Diagnosis of Diabetes Mellitus and Intermediate Hyperglycemia : Report of a WHO/IDF Consultation. Geneva: WHO Document Production Services; 2006.

48. World Health Organization. Diabetes mellitus : report of a WHO Study Group. World Health Organ Tech Rep Ser. 1985;727:1-113.

49. Wallace TM, Levy JC, Matthews DR. Use and abuse of HOMA modeling. Diabetes Care. 2004;27:1487-95.

50. van Riet E, Wuhrer M, Wahyuni S, Retra K, Deelder AM, Tielens AG, et al. Antibody responses to Ascaris-derived proteins and glycolipids: the role of phosphorylcholine. Parasite Immunol. 2006;28:363-71.

51. Uh HW, Hartgers FC, Yazdanbakhsh M, Houwing-Duistermaat JJ. Evaluation of regression methods when immunological measurements are constrained by detection limits. BMC Immunol. 2008:9:59.

\section{Submit your next manuscript to BioMed Central and take full advantage of:}

- Convenient online submission

- Thorough peer review

- No space constraints or color figure charges

- Immediate publication on acceptance

- Inclusion in PubMed, CAS, Scopus and Google Scholar

- Research which is freely available for redistribution 